\title{
Reflection as a Skill-Clinical Supervision as a Prerequisite for Professional Development to Ensure Patient Safety
}

\author{
Eva Røed Røsnæs, Anne Lind Jølstad, Elisabeth Severinsson, Anne Lyberg \\ The Centre for Women's, Family and Child Health, Department of Nursing and Health, Faculty of Health and Social Sciences, \\ University College of Southeast Norway, Kongsberg, Norway \\ Email: Eva.Rosnes@usn.no
}

How to cite this paper: Røsnæs, E.R., Jølstad, A.L., Severinsson, E. and Lyberg, A. (2017) Reflection as a Skill-Clinical Supervision as a Prerequisite for Professional Development to Ensure Patient Safety. Open Journal of Nursing, 7, 979-992. https://doi.org/10.4236/ojn.2017.79072

Received: July 5, 2017

Accepted: September 4, 2017

Published: September 7, 2017

Copyright $\odot 2017$ by authors and Scientific Research Publishing Inc. This work is licensed under the Creative Commons Attribution International License (CC BY 4.0).

http://creativecommons.org/licenses/by/4.0/

\begin{abstract}
This study is set in the context of the final phase of nurse specialist students' (NSS) postgraduate education in surgical, oncological, anaesthesia and intensive care nursing at the University College in June 2015. The aim was to explore NSSs' experiences of clinical supervision (CS) during their postgraduate clinical education. 46 NSS answered open-ended questions and their responses were analysed by means of a qualitative content analysis. The response rate was $82 \%$. One main theme emerged: CS as a prerequisite for professional development and two domains: A reflective way of growing and learning through CS and The meaning of being and acting in a reflective and professional manner to ensure patient safety (PS). The results indicate that reflection is a crucial part of the NSS' experiences of CS during their postgraduate clinical education. The supervisor's ability to confirm the students, mutual trust and feeling safe in the relationship with the supervisor are of great importance. The students highlighted the value of continuity in CS and being supported yet challenged. The supervisor has great responsibility for the NSS' development of professional clinical competence. The supervisor's personal and professional skills, in addition to her/his ability to provide CS are important for PS as well as for professional and interdisciplinary teamwork. Acting in a reflective and professional manner is of great importance for ensuring PS. Although most of the students reported being sufficiently competent to ensure PS and agreed that CS and reflection are of great importance for PS, they wanted more time to reflect on their actions together with their supervisor. In conclusion, CS has the potential to lead to quality improvement. However, in order to enhance reflective practice, which is a prerequisite for CS and PS, we recommend closer cooperation between the university college and clinical supervisors, as well as a formal master level education for clinical supervisors.
\end{abstract}




\section{Keywords}

Clinical Supervision, Nurse Specialist Student, Postgraduate Education, Patient Safety, Reflection

\section{Introduction}

According to the Norwegian White Paper No. 16 (2016-17) "Culture for Quality in Higher Education" [1], the overall goal of nursing education is to produce reflective practitioners. Educating nurse specialist students (NSS) who possess these capabilities is complex. Reflection and reflective practice in nurse specialist education are considered essential for specialized professional competence. The students should be able to act and think professionally, integrating theory and practice from the outset. Reflective practice was increasingly focused upon in the literature from the 1990s [2]. According to Atkins [3] and Duffy [4], reflective practice is defined as a learning and development process that includes selfexamination of one's professional practice, experiences, thoughts, emotions, actions and gaining knowledge that can enrich it. Clinical practice is a crucial part of the postgraduate education of NSS in Norway, comprising $50 \%$ of the education.

The focus of this study is the final part of the NSS' postgraduate education in anaesthesia, intensive care, surgical and oncology nursing at the University College in June 2015. Specialist nursing practice entails encountering people in vulnerable and exposed situations. Specialist nurses have to function in complex health care systems, continuously refresh and update their skills and knowledge, in addition to framing and solving complex patient and healthcare problems [5]. At the same time, their work has become significantly more complex and they are under pressure to be efficient, making patient safety (PS) a hot topic. In Norway, most clinical nurse supervisors have no formal qualifications or training for supervision. However, the supervisors' skills are significant for the quality of supervision and they are in a unique position to facilitate learning processes and promote the students' professional growth and identity building as specialist nurses [6]. To enhance the students' professional development, a systematic structure can lead to positive outcomes in terms of quality and PS [7].

Healthcare delivery today comprises many benefits and challenges. Clinical supervision (CS) is one of the keys to maintaining and improving the overall quality of care, the professional development of personnel as well as patient and staff retention [8].

CS is increasingly recognized as a vital part of effective, modern healthcare systems [9]. There are several definitions of CS in the literature. Proctor [10] includes three elements in his definition of the supervision process: formative, which means development, normative, which implies a standard setting and restorative, which indicates the provision of support. According to Severinsson 
[11], three main concepts should be established in nursing supervision: confirmation, meaning and self-awareness. The general target of clinical supervision is to support the development of the supervisee's job identity, competence, skills and ethics. The purpose of CS is to improve the quality of the nurse-patient relationship in terms of identifying and fulfilling a patient's care needs in order to achieve a positive change that can be observed and measured. In such a process, the supervisee together with a more experienced practitioner can reflect on practice using case material in order to learn and refine skills [12]. In this paper, we adopted the definition from Bishop's study, as it explains the importance of reflection and the fact that the focus of CS should be to ensure a safe and supportive environment that promotes the delivery of quality of care: "Clinical supervision is a designed interaction between two or more practitioners within a safe and supportive environment, that enables a continuum of reflective critical analysis of care to ensure quality patient services, and the well-being of the practitioner" [13] (p. 113).

Bishop's study highlights reflection as a skill and a core area of CS. A search of the literature revealed that while there are many articles on the subject of reflection, few studies have linked it with NSS. Carroll et al. [14] claim that there is no clear definition of reflection or reflective practice and that the plethora of terms used interchangeably in the literature make the phenomenon difficult to utilize within nursing education. However, the present study first demonstrates that reflection leads to a new understanding and the intention to act differently in the future (an iterative dimension). Secondly, it shows different levels of reflection on experience. In general, the surface level is more descriptive and less analytical than the deeper level, which appears more difficult to reach. Dewey [15] focused on the depth and quality of reflective thinking, which is termed a vertical dimension. Dubé and Ducharme [2] also refer to the definitions of Boud et al. [16], Dewey [15], Mezirow [17], Reid [18] and Schön [19]. Dubé and Ducharme [2] found that in all the studies the definitions of reflective practice identified the experience as the basis for new learning. In most studies, the process refers to Schön's [19] reflection-in-action which means reflection during a clinical experience and reflection-on-action in the sense of reflection on a clinical experience after the fact. The work of Mezirow [17] indicates that the reflection process can operate at various levels of intensity: habitual action, thoughtful action, reflection or critical reflection. Studies by Callister et al. [20], Cooper et al. [21], Honey et al. [22] and Glaze [23] show that student nurses managed to develop reflective skills such as self-awareness, openness to others and their practices by following reflective practice in an academic context, as well as the various emotions experienced in a learning context, such as fear or anxiety.

NSS are educated and trained to work in high-tech departments with a strong focus on PS. Nowadays PS is increasingly recognized as a key dimension of quality care and has been integrated into the education of healthcare professionals [24]. Jha et al. [25] claim that despite the traditional principle of "do no harm", 
unsafe medical care seems to cause significant morbidity and mortality all over the world. In particular, surgery and anaesthesia present substantial safety risks. In the US, estimates suggest that surgical adverse events account for $48 \%$ of all adverse events. The relevance of PS has expanded internationally [26]. With the complexity of today's healthcare system, the successful treatment and outcome of each patient depend upon a range of factors. Many different types of healthcare professional are involved and it is difficult to ensure safe care unless the system is designed to facilitate timely and complete information and understanding by all. Accordingly, numerous factors such as understaffing and inadequate structures contribute to unsafe patient care [27]. The strategy includes the specific goal of improving PS and the quality of the healthcare services. The main dimension in PS and safety culture domains is respectful communication, which implies sharing experiences. Furthermore, the most important dimensions in the multidisciplinary capacity building domain are collaboration and teamwork, coordination and risk management, knowledge sharing and patientcentred communication [26].

\section{Methods}

\subsection{Design}

The study has a qualitative design [28]. In 2015, we conducted a quantitative survey that included qualitative questions focusing on how NSS experienced CS from their supervisors in relation to PS [29]. These qualitative questions constitute the empirical material in this study.

\subsection{Sample}

The study included all the 56 nurse specialist students (NSS) from four healthcare contexts in the final phase of their postgraduate education at the University College in June 2015 and eligible to participate in the study. In total, 46 NSS (8 anaesthesia, 11 intensive care, 14 operation/surgical and 13 oncological care) completed and returned the anonymous questionnaire to the first and the second author. The response rate was $81 \%$.

The open questions focused on experiences of CS and competencies in order to ensuring PS: a) In CS I am particularly pleased with ... b) In CS I would prefer changes to... c) How do you understand the concept of PS? d) Do you have the right competence to ensure PS? e) How can CS be important for PS? The characteristics of the participants are presented in Table 1.

\subsection{Data Analysis}

In order to analyse the questions we applied Graneheim and Lundman's [30] qualitative content analysis, a method for analysing written or verbal communication in a systematic way. A common component of qualitative interpretive content analysis methods is coding operations that translate one set of meanings into the other. The method presented by Graneheim and Lundman [30] consists 
Table 1. Demographic characteristics of the students.

\begin{tabular}{cc}
\hline Sample characteristics & $\mathrm{N}=46$ \\
\hline Age, years, med(q1-q3) & $36.5(31.0-39.3)$ \\
Female gender & $42(91.3 \%)$ \\
Previous work experience, years, med & (q1-q3) \\
Speciality, No (\%) & $10.0(6.0-13.3)$ \\
Anaesthesia & \\
Intensive care & $8(17.4 \%)$ \\
Operation/Surgery & $11(23.9 \%)$ \\
Oncology & $14(30.4 \%)$ \\
Female supervisor & $13(28.3 \%)$ \\
\end{tabular}

of the following steps: identifying meaning units, condensing, abstracting, coding, categorising and developing themes. In the analysis process of this study, both the first and the second author read the material repeatedly and identified the sense of the whole for each question. Meaning units were then identified through joint reflection and discussion, after which they were categorized into ten subthemes and five themes. All the authors carefully discussed the tentative subthemes and themes. Having moved back and forth several times between the whole and the parts of the text, all the authors finally agreed on the condensing of the domains and key components in accordance with Baxter [31]. According to Baxter [31], interpretive content analysis enables a deeper understanding of the meaning of the content. Finally, we compiled one main theme, two domains, of which one was on the latent level and one on the manifest level, and four key components as presented in Table 2.

\subsection{Ethical Considerations}

The guidelines for research set out in the Helsinki declaration [32] were followed. The study was approved by the Head of the Institute of Nursing and the Dean of the Faculty of a University College on the east coast of Norway. In addition, we applied to the Norwegian Centre for Research Data for approval (No. 53410). The principles of confidentiality, voluntariness and informed consent were adhered to. Information about the aim of the study was provided both in writing and verbally. The participants indicated their consent by giving a completed consent form to their principal tutor. The data were stored securely in a fireproof cabinet in accordance with university college regulations.

\section{Results}

Overall, the results indicate that reflection is a crucial part of the NSS' experiences of CS during their postgraduate clinical education. The NSS also highlighted the importance of being understood in their role as a student. They re- 
Table 2. Main theme, domains and key components of the nurse specialist students' experiences of clinical supervision (CS) during their postgraduate clinical education.

\begin{tabular}{cc}
\hline \multicolumn{3}{c}{ Main theme: } \\
CS as a prerequisite for professional development \\
\hline Domain 1 \\
Manifest level \\
A reflective way of growing and \\
learning through CS
\end{tabular}

flected on the concept of CS in relation to PS and emphasized factors such as safe care, person-centred care, evidence-based practice and teamwork. Most of the students reported that they are sufficiently competent to ensure PS and that CS and reflection are of great importance for PS. Most of the students were especially satisfied with the supervision and their supervisor. One main theme emerged: $C S$ as a prerequisite for professional development and two domains; $A$ reflective way of growing and learning through CS, (manifest level) with two key components and The meaning of being and acting in a reflective and professional manner to ensure PS (latent level), also with two key components (Table 2).

\subsection{Clinical Supervision as a Prerequisite for Professional Development}

Based on the results, the main theme comprises the NSS' need for more time to reflect together with their supervisor. According to the students, learning to reflect and act in a professional and reflective way through CS is a prerequisite for professional development. The results also show that CS is of great importance for PS.

\subsubsection{A Reflective Way of Growing and Learning through Clinical Supervision}

This manifest domain concerns key components such as the importance of reflection and the supervisor's ability to provide CS. The students reported the importance of reflection in practice, that CS is planned and well organized for them. Stability and continuity in the relationship with the supervisor is important in CS. To achieve this they suggested the need for the same supervisor over time, or even two supervisors for each student, which would enable a more nuanced learning situation. Having the same supervisor during the clinical practice period created trust, safety, stability and a close relationship with the supervisor. Most of the students reported a desire for more time together with their supervisor. One student stated:

I would have liked more time together with my supervisor, more time to reflect and discuss patient situations in a setting away from the patient.

In this study, the need for time was consistently expressed as essential. The desire for time to reflect, discuss and summarize together with their supervisors 
at the end of each day demonstrates the need for both mental and physical reflection space.

The NSS described PS as encompassing the principles of not causing harm, taking care of the patient when she/he is unable to do so, attending to injuries, preventing infections, decubitus and hypothermia, as well as ensuring that the patient's physical, mental, social and spiritual needs are met in a dignified manner. A high level of nursing competence and expertise, evidence-based practice, user empowerment, good practical skills, in addition to sufficient resources, positive attitudes and good role models at the workplace are of importance. Being encouraged and feeling free to ask questions and call for help were also mentioned as essential.

The NSS described the supervisor's personal and professional skills as crucial for the beneficial outcome of supervision. One student stated: For me, the supervisor's personal skills, her openness, generosity and kindness to me are important.

Another NSS expressed: I appreciate that the supervisor is patient, supportive and willing to teach me. It is ok to be new and inexperienced, because the student and supervisor become familiar with each other and the relationship increases the student's confidence.

One of the NSS described the supervisor's professional competence as: For me, professional competence means that my supervisor has knowledge, experience and clinical skills and is willing to teach and communicate.

The NSS highlighted the supervisor's ability to communicate, as well as professional and interdisciplinary teamwork as important for PS.

\subsubsection{The Meaning of Being and Acting in a Reflective and Professional Manner to Ensure Patient Safety}

This latent domain concerns key elements such as substance of CS and healthcare professionals responsibility to ensure patient safety. The NSS reported that prerequisites for CS are the supervisor's ability to be open, generous and friendly. They wanted to be seen, accepted, respected, appreciated and recognised, which could be interpreted as their need for confirmation. Furthermore, they described the importance of mutual trust and feeling safe in the relationship with the supervisor. The NSS also mentioned the need to be supported yet challenged in the CS process:

As a specialist nurse student, I want to be challenged by my supervisor and given the opportunity to work more independently with patients. The supervisor should have patience, provide support and see me as a person.

The meaning of being and acting in a reflective and professional manner is that the students' experiences constitute the essential substance and core content of CS. The meaning comprises elements such as confirmation, affirmation, trust, being supported yet challenged, dialogue and identifying role models. All of the students wanted more time for dialogue and to reflect together with the supervisor. Some also wanted the supervision to be communicated in a more respon- 
sive way and space for asking "silly" questions.

The NSS described supervision as being of great importance for ensuring PS. In the concept of PS, the NSS emphasized areas such as evidenced-based practice, attitudes, safeguarding the patient's dignity, working properly and delivering high quality care and treatment.

It was essential to reflect together with the supervisor in order to learn from adverse events and identify alternative ways of acting. One student illustrated this as follows:

Supervision increases my self-awareness in new patient situations that I did not experience before. Reflecting together with my supervisor increases my understanding and is of great importance for patient safety.

Another student expressed:

Supervision increases my learning, my self-awareness and develops my professional competence and team-working skills. It is important to benefit both personally and professionally from the supervisor's experience and competence.

The result indicates that the supervisor has a great responsibility for the NSS' development and achievement of clinical competence. One of the students expressed:

Supervision is important for patient safety, but it depends on the form of supervision and the supervisor's competence.

Supervisors who assume this responsibility transfer their knowledge and values to ensure the students' development and responsibility for patient safety. Supervisors who do not take responsibility may fail to contribute to the students' professional development.

\section{Discussion}

The aim of this study was to investigate NSS' experiences of CS during their postgraduate clinical education. The main theme: "CS as a prerequisite for professional development" reflects the interpretation of the NSS' descriptions of what they appreciated in CS and what they would like changed. Two research questions were addressed: 1 . What elements of CS do NSS emphasize as essential for their professional development? 2. How does CS support the PS competencies of NSS?

\subsection{Elements of Clinical Supervision That Emphasize Nurse Specialist Students' Professional Development}

The findings in our study emphasize reflection as a crucial part of the NSS' experiences of CS during their postgraduate clinical education and for ensuring PS. The NSS stated that a prerequisite is educated professional supervisors who can influence their development of a professional identity [38]. The NSS highlighted elements of CS such as the supervisor's ability to be open, generous and friendly. Furthermore, they described the importance of the supervisor's professional and personal competence. In addition, the NSS wanted to be more challenged in the 
CS process. A study by Pack [40] underlines the fact that a supervisor's personal qualities such as 'willingness and preparedness to show understanding, bringing out genuine feelings, confirming and being sensitive to the supervisee's needs' are considered important [39]. There are a number of key prerequisites for enriching the environment in which the supervisee's awareness can grow and flourish [40]. Supervisors need to be aware of the purpose of their role, as well as adequately prepared and trained to confirm and find emphatic ways to offer constructive critique of their supervisee's practice but avoid shaming and humiliation [40].

Most NSS were pleased with the supervision they received and they were satisfied with their supervisor. Nevertheless, they strongly emphasized the desire for even more time to reflect with their supervisor. However, finding time and room for supervision and reflection is a challenge. Moreover, NSS particularly pointed out the need for additional time to reflect outside of patient situations. A quiet room without risk of interference would be the preferred location in which to discuss and reflect on their experiences of patient situations, as a means of achieving more strategies for action. Ekebergh [33] claims that to achieve a real reflection one has to distance oneself from the situation and make it possible for the conscious mind to completely turn towards itself and that to achieve self-reflection, one must 'step out' of the situation and actions. Ekebergh [33] also argues that as a consequence, reflection and self-reflection are not possible while acting, but only at a later stage after the action has taken place. This underpins the NSS' need for time to reflect outside patient situations. CS is a prerequisite for professional development and essential for growing and learning and for being and acting in a reflective and professional manner, which highlights the supervisor's ability to provide CS and the substance of CS. The need for both mental and physical reflection space was considered essential.

Furthermore, the NSS stated that the supervisor's personal and professional qualities are vital for both supervision and continuity. A study by Platzer et al. [34] found that reflective practice groups for student nurses provided emotional support, reassurance, feedback, encouragement and constructive criticism from peers, in addition to enabling changes in behaviour and attitude among the participants. Reflective practice seems to be a new learning tool for the development of different reflective skills. Gibb's reflective cycle [35] and Mezirow's [17] level of reflectivity demonstrate that reflection consists of different stages or levels and follows a given order [33]. Ekebergh [33] claims that from a lifeworld perspective the use of reflection models might be risky, especially if slavishly followed, because the complexity of reflection can never be reduced to different stages. Reflection is lived and must be supported in an open, sensitive and flexible manner in relation to the learner. Ekebergh [33] states that following a structure or model without any attention to the learner's lifeworld will not enhance learning. Furthermore, Ekebergh argues that this aspect of using reflection models has received little attention in the literature about reflective practice. Lifeworld 
experiences concern how each student experiences her/his caring situations, patients and colleagues [33].Ekebergh [36] understands reflection as a comprehensive act of human consciousness, where reflection on thoughts, feelings and experiences creates a meaningful picture of a human being's experience of the world. This perspective highlights the fact that reflection is a way to both grow and learn through CS. A study by Severinsson [37] concludes that spending more time reflecting on individual students' experiences of clinical situations within the nursing education will affect the students' personal knowledge as well as the integration of theory and practice. From this perspective, more reflection will reduce the gap between theory and clinical practice [37].

\subsection{How does Clinical Supervision Support Nurse Specialist Students' Patient Safety Competencies?}

With regard to PS, the NSS stated that reflection increased their self-awareness and provided them with more options for dealing with unfamiliar patient situations. Reflection has the potential to enable them to learn from mistakes and think critically about their own practice, thus ensuring quality care and treatment. The NSS wanted more constructive feedback and to be challenged in supervision in order to acquire new perspectives and be able to prevent adverse events. Traditionally NSS receive CS with little time for reflection outside the patient situations. At present, the teachers at the university college have had little influence on the substance and structure of the supervision. According to Severinsson [11], three main concepts should be established in nursing supervision: confirmation, meaning and self-awareness. Confirmation concerns being confirmed and can lead to growth of professional identity and increase the supervisees' self-confidence and self-knowledge. The main goal of confirmation is to eliminate doubt and ensure that the supervisee develops a professional identity [38]. To be loved and confirmed is the genuine and deepest wish of all human beings [38]. NSS expressed this very need to be seen as a person and understood in their student role. Holm Wiebe et al. [38] point out that confirmation requires active listening and the ability to put oneself in the other person's situation, followed by verbally confirming her/him. If a student is incapable of accepting confirmation from her/his supervisor, it could undermine her/his identity development [38]. Meaning is understood by Severinsson [11] as the meaning of existence experienced in CS which is related to supervisors' competence and moral responsibility. Self-awareness is built on the process of learning through CS and should lead to growth and development [11]. According to Altmiller [6], the supervisor's role is of great importance for the quality of supervision. Supervisors are in a unique position to facilitate learning processes and promote the students' professional growth and identity building as specialist nurses. Berggren and Severinsson [7] concluded that to enhance the students professional development, a systematic structure can lead to positive outcomes in terms of quality and PS. Another prerequisite for professional development is time to reflect, 
discuss and summarize together with the supervisor in order to learn from adverse events and increase future specialist nurses' awareness of their responsibility for ensuring PS. In the study by Jølstad et al. [29] the researchers concluded that CS is crucial for ensuring PS.

\subsection{Limitations of the Study}

The 46 NSS received five qualitative open-ended questions. Some students did not answer all the questions and many of the responses consisted of short sentences or keywords. Focus groups could be used to achieve a deeper understanding of how NSS experience CS in relation to PS, as this method permits researchers to enter the participants' world. According to Liamputtong [41], it is an ideal approach for examining experiences, stories, points of view, beliefs, needs and individual concerns. The interaction and the group process assist people to explore and clarify their beliefs and experiences, while at the same time enabling researchers to uncover aspects of understanding that often remain hidden. The results of this study are only valid for the study group. It would be of interest to compare different groups of students at postgraduate educational level and their experiences of CS and possibilities for reflection upon practice.

\section{Conclusion}

In conclusion, there is a potential for improving the quality of CS in clinical education. We recommend closer cooperation between the university college and clinical supervisors in order to enhance reflective practice, which is a prerequisite for CS and PS. In addition, we recommend that the university college should provide formal education at master level for clinical supervisors in order to increase their supervisory skills and awareness of their responsibility for the professional development of NSS. The competence of future nurse specialists is of the utmost importance, as they will be in a key position to ensure safe healthcare.

\section{Contributions}

The study was designed by E.S. and A.L. A.L. coordinated the research. E.R. and A.L.J. performed the data collection. E.R. and A.L.J. contributed to the study conception and literature search, supported by the specialized librarian at the university college. All authors in the research team participated in the data analysis. E.R. and A.L.J. were responsible for drafting the manuscript. All authors contributed to the intellectual content of the paper. The study was supervised by E.S. and A.L.

\section{Acknowledgements}

The authors wish to thank the nurse specialist students for participating in the study and Monique Federsel for revising the English language. This research was funded by the The Centre for Women's, Family \& Child Health, University Col- 
lege of Southeast Norway.

\section{References}

[1] Ministry of Education. White Paper No. 16 (2016-2017) Culture for Quality in Higher Education. Solberg Government, Ministry of Education, Oslo.

[2] Dubé, V. and Ducharme, F. (2015) Nursing Reflective Practice: An Empirical Literature Review. Journal of Nursing Education and Practice, 5, 91-99. https://doi.org/10.5430/jnep.v5n7p91

[3] Atkins, S. (2004) Reflective Practice in Nursing. In: Bulman, C. and Schutz, S., Eds., 3rd Edition, Blackwell Publishing, Carlton.

[4] Duffy, A. (2007) A Concept Analysis of Reflective Practice: Determining Its Value to Nurses. British Journal of Nursing, 16. https://doi.org/10.12968/bjon.2007.16.22.27771

[5] Mann, K., Gordon, J. and MacLeod, A. (2009) Reflection and Reflective Practice in Health Professions Education: A Systematic Review. Advances in Health Sciences Education, 14, 595-621. https://doi.org/10.1007/s10459-007-9090-2

[6] Altmiller, G. (2011) Quality and Safety Education for Nurses Competencies and the Clinical Nurse Specialist Role. Implications for Preceptors. Clinical Nurse Specialist, 25, 28-32. https://doi.org/10.1097/NUR.0b013e318201f830

[7] Berggren, I. and Severinsson, E. (2011) The State of the Science of Clinical Supervision in Europe. In: Cutcliffe, J., Hyrkäs, K. and Fowler, J., Eds., Routledge Handbook of Clinical Supervision: Fundamental International Themes, Milton Park, Abingdon, Oxon, 327-337.

[8] Fowler, J. and Cutcliffe, J.R. (2011) Clinical Supervision. Origins, Overviews and Rudiments. In: Cutcliffe, J., Hyrkäs, K. and Fowler, J., Eds., Routledge Handbook of Clinical Supervision: Fundamental International Themes, Milton Park, Abingdon, Oxon, 8-19.

[9] Milne, D. (2007) An Empirical Definition of Clinical Supervision. British Journal of Clinical Psychology, 46, 437-447. https://doi.org/10.1348/014466507X197415

[10] Proctor, B. (1991) Supervision: A Co-Operative Exercise in Accountability. Enabling and Ensuring: Supervision in Practice. In: Marken, M. and Payn, M., Eds., National Bureau and Council for Education and Training in Youth and Community Work, Leicester, 21-23.

[11] Severinsson, E.I. (2001) Confirmation, Meaning and Self-Awareness as a Core Concept of the Nursing Supervision Model. Nursing Ethics, 8, 36-44. https://doi.org/10.1177/096973300100800105

[12] Severinsson, E.I. (1995) Clinical Nursing Supervision in Health Care. The Nordic School of Public Health, Göteborg.

[13] Bishop, V. (2011) Clinical Supervision and Clinical Governance. In: Cutcliffe, J., Hyrkäs, K. and Fowler, J., Eds., Routledge Handbook of Clinical Supervision: Fundamental International Themes, Milton Park, Abingdon, 327-337.

[14] Carroll, M., Curtis, L., Higgins, A., Nicholl, H., Redmond, R. and Timmins, F. (2002) Is There a Place for Reflective Practice in the Nursing Curriculum? Nurse Education in Practice, 2, 13-20. https://doi.org/10.1054/nepr.2002.0050

[15] Dewey, J. (1933) How We Think, a Restatement of the Relation of Reflective Thinking to the Educative Process. No. 370.15 D48.

[16] Boud, D., Keogh, R. and Walker, D. (2013) Reflection: Turning Experience into Learning. Routledge. 
[17] Mezirow, J. (1991) Transformative Dimensions of Adult Learning. Jossey-Bass, San Francisco.

[18] Reid, B. (1993) “But We're Doing It Already!” Exploring a Response to the Concept of Reflective Practice in Order to Improve Its Facilitation. Nurse Education Today, 13, 305-309.

[19] Schön, D.A. (1984) The Reflective Practitioner: How Professionals Think in Action. Vol. 5126, Basic Books.

[20] Callister, L.C., Luthy, K.E., Thompson, P. and Memmott, R.J. (2009) Ethical Reasoning in Baccalaureate Nursing Students. Nursing Ethics, 16, 499-510. https://doi.org/10.1177/0969733009104612

[21] Cooper, C., Taft, L.B. and Thelen, M. (2005) Preparing for Practice: Students' Reflections on Their Final Clinical Experience. Journal of Professional Nursing, 21, 293-302.

[22] Honey, M., Waterworth, S., Baker, H. and Lenzie-Smith, K. (2006) Reflection in the Disability Education of Undergraduate Nurses: An Effective Learning Tool? Journal of Nursing Education, 45, 449-453.

[23] Glaze, J.E. (2002) Stages in Coming to Terms with Reflection: Student Advanced Nurse Practitioners' Perceptions of Their Reflective Journeys. Journal of Advanced Nursing, 37, 265-272. https://doi.org/10.1046/j.1365-2648.2002.02093.x

[24] Okuyama, A., Martowirono, K. and Bijnen, B. (2011) Assessing the Patient Safety Competencies of Healthcare Professionals: A Systematic Review. BMJ Quality \& Safety, 1-11. https://doi.org/10.1136/bmjqs-2011-000148

[25] Jha, A.K., Prasopa-Plaizier, N., Larizgoitia, I. and Bates, D.W. (2010) On Behalf of the Research Priority Setting Working Group of the WHO World Alliance for Patient Safety. Patient Safety Research: An Overview of the Global Evidence. Quality Safe Health Care, 19, 42-47. https://doi.org/10.1136/qshc.2008.029165

[26] Severinsson, E., Haruna, M., Rönnerhag, M., Holm, A.L., Hansen, B.S. and Berggren, I. (2017) Evidence of Linkages between Patient Safety and Person-Centred Care in the Maternity and Obstetric Context-An Integrative Review. Open Journal of Nursing, 7, 378-398. https://doi.org/10.4236/ojn.2017.73030

[27] Walton, M. and Barraclough, B. (2011) Patient Safety Curriculum Guide Multi-Professional Edition. World Health Organisation, Malta.

[28] Polit, D.F. and Beck, C.T. (2013) Essentials of Nursing Research: Appraising Evidence for Nursing Practice. Lippincott Williams \& Wilkins, Philadelphia.

[29] Jølstad, A.L., Røsnæs, E.R., Lyberg, A. and Severinsson, E. (2017) Clinical Supervision and Non-Technical Professional Development Skills in the Context of Patient Safety-The Views of Nurse Specialist Students. Open Journal of Nursing, 7, 253-267. https://doi.org/10.4236/ojn.2017.72021

[30] Graneheim, U.H. and Lundman, B. (2004) Qualitative Content Analysis in Nursing Research: Concepts, Procedures and Measures to Achieve Trustworthiness. Nurse Education Today, 24, 105-112.

[31] Baxter, L.A. (1991) Content Analysis. Studying Interpersonal Interaction, 239-254.

[32] World Medical Association Declaration of Helsinki (2008) Ethical Principles for Medical Research Involving Human Subjects. Adopted by the 59th WMA General Assembly, Seoul. http://www.wma.net

[33] Ekebergh, M. (2007) Lifeworld-Based Reflection and Learning: A Contribution to the Reflective Practice in Nursing and Nursing Education. Reflective Practice, 8 , 331-343. https://doi.org/10.1080/14623940701424835 
[34] Platzer, H., Blake, D. and Ashford, D. (2000) An Evaluation of Process and Outcomes from Learning through Reflective Practice Groups on a Post-Registration Nursing Course. Journal of Advanced Nursing, 31, 689-695. https://doi.org/10.1046/j.1365-2648.2000.01337.x

[35] Gibbs, G. (1988) Learning by Doing: A Guide to Teaching and Learning Methods.

[36] Ekebergh, M. (2001) Assignment of Health Science Knowledge: The Importance of Reflection for Learning. Doctoral Dissertation, Department of Health Sciences, Åbo Academy, Vasa.

[37] Severinsson, E.I. (1998) Bridging the Gap between Theory and Practice: A Supervision Programme for Nursing Students. Journal of Advanced Nursing, 27, 1269-1277. https://doi.org/10.1046/j.1365-2648.1998.00644.x

[38] Holm Wiebe, A.K., Johansson, I., Lindquist, I. and Severinsson, E. (2011) Nurses' Experiences of Core Phenomena in the Supervisor Training Programme. Routledge Handbook of Clinical Supervision. Fundamental International Themes, New York, 241-249.

[39] Severinsson, E.I. and Hallberg, I.R. (1996) Clinical Supervisors' Views of Their Leadership Role in the Clinical Supervision Process within Nursing Care. Journal of Advanced Nursing, 24, 151-161. https://doi.org/10.1046/j.1365-2648.1996.17321.x

[40] Pack, M. (2009) Clinical Supervision: An Interdisciplinary Review of Literature with Implications for Reflective Practice in Social Work. Reflective Practice, 10, 657-668. https://doi.org/10.1080/14623940903290729

[41] Liamputtong, P. (2011) Focus Group Methodology: Principle and Practice. Sage Publications.

\section{Submit or recommend next manuscript to SCIRP and we will provide best} service for you:

Accepting pre-submission inquiries through Email, Facebook, LinkedIn, Twitter, etc. A wide selection of journals (inclusive of 9 subjects, more than 200 journals)

Providing 24-hour high-quality service

User-friendly online submission system

Fair and swift peer-review system

Efficient typesetting and proofreading procedure

Display of the result of downloads and visits, as well as the number of cited articles

Maximum dissemination of your research work

Submit your manuscript at: http://papersubmission.scirp.org/

Or contact ojn@scirp.org 